\title{
CATULO DA PAIXÃO CEARENSE: a derradeira vítima de Odete Roitman
}

Benito Martinez Rodriguez ${ }^{*}$

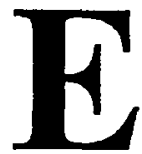

m 1929, no velório de José Carlos do Patrocinio, o Zeca, fillho do célebre Tigre da Abolição, Manucl Bandeira ouve de Sinhô, entre os clogios ao amigo desaparecido, suas críticas a "tudo quanto era músico e poeta", e acrescenta Bandeira que o sambista "estava danado naquela época com o Villa[-Lobos] e o Catullo [da Paixão Cearense], poeta era ele, músico cra ele".

Na década de 40, já no tinal de sua vida, Catulo da Paixão Cearense, sob o pretex to de introduzir a edição de sua "ópera verde", 2 O milagre de São João, produz uma pequena síntese, a um tempo imodesta e amargurada, de sua trajetória artística. O desabato volta-se sobretudo contra scus colegas [adversários!] no cenário musical:

* Universidade Federal do Paraná.

1 BANDEIRA, Manuel. Crônica da Provincia do Brasil, p. 108-110.

2 A expressão é citada por Mário Jose de Almeida, que assina breve prefácio ao mesmo livro, atribuindo-a a Procópio [Ferreira?]. CEARENSE, Catullo da Paixão. O milagre de São João. p.l. 
Hoje, no Brasil, polulam (sic) os "bardos nacionais" e nenhum deles deixa de compor sua marchinha, seu samba ou sua cançāo, falando sempre na "cabocla", no "malandro", no "Brasil pandeiro", nome este acapadoçado, que até melindra a nossa brasilidade. Os célebres trovadores, não sei porque, fizeram dos morros o seu Parnaso, esses lugares evitados em outros tempos por todas as pessoas decentes. Os morros, com os seus desordeiros e os seus assassinos nos apavoravam! Hoje são aclamados por senhoras e senhores da alta nobresa (sic)!!! Basta que um sujeito escreva um samba, em que, capadoçalmente, fale em Brasil, para que logo seja considerado um poeta de vôos nacionais. Agora, tudo é Brasil, Brasil, Brasil, e, no entanto, há 50 anos, quando eu já dedicava os meus descantes ao Brasil brasileiro, era chamado de maniaco, porque só cantava a minha pátria. ${ }^{3}$

A disputa entre o "Rei do Samba" e o campeão da modinha, que ainda parecia incomodar Sinhô, em fins dos anos 20 , já fora completamente vencida pelo sambista no início da década de 40 . Note-se que não se tratava de uma conquista pessoal, alcançada na disputa particular entre os dois artistas populares. Sinhô morrera cm 1930, enquanto Catulo viveria até 1946. Como bem revela o depoimento do veterano artista, os cancionistas vitoriosos daqueles tempos dedicavam-se à marcha ou ao samba, isto é, ao gênero que veio a constituir-se no eixo fundamental da cançĩo popular urbana no Brasil moderno, legítimo vencedor daquela disputa: o samba urbano carioca.

O contraste entre samba e modinha, visto a partir da perspectiva do confronto entre os dois mestres destas modalidades, poderia parecer demasiado esquemático: o novo gênero, popular, moderno, massilicado (o samba), $\mathrm{cm}$ oposição ao tradicional, semifolclórico, artesanal, original (a modinha). É preciso matizar esse contraste.

A modinha, canção amorosa cujos primeiros registros são ainda do século XVIII, é a mais antiga das formas musicais populares de caráter urbano

3 CEARENSE, Catulo da Paixĩo. Op. cit., p. 7. 
produzidas no Brasil. Evoluída a partir de matrizes européias, ganhou em nosso país uma característica própria que foi repetidamente ressaltada por aqueles que escreveram sobre nossa realidade durante o século passado. ${ }^{4}$

Ao caminharmos para o século $\mathrm{XX}$, a velha modinha, $\mathrm{já}$ veterana de um século nas festas e reuniões sociais, entrara $\mathrm{cm}$ franco declínio. Nesta época, após enfrentar durante todo o século XIX a concorrência/influência de ritunos vindos da Europa (scottisch, mazurca, polca), a modinha finalmente cedia seu lugar privilegiado na preferência popular ao samba. O momento desta "passagem de cetro" da modinha ao gênero de canção forjado nas rodas da casa de Tia Ciata corresponde aos anos que vão de 1915 até o final da década de 20 aproximadamente. Não por acaso, durante esse periodo, as grandes cidades brasileiras, em particular a capital, passam por acentuado crescimento, experimentando um vigoroso surto de modernização material que alcança em cheio o mundo musical. É a época em que se consolida a indústria fonográfica no país; o rádio passa de empreendimento experimental e de fins essencialmente educativos a uma promissora indústria de entretenimento e variedades; o teatro popular musicado abandona as formas tradicionais das Revistas do Ano e começa a adotar o formato que desembocaria no moderno Teatro de Revista, com as vedetes e os espetáculos de "rebolado"; o cinema nacional, de forma ainda incipiente, prepara-se para produzir seus primeiros sucessos populares, especialmente no final da década de 20 (e na década seguinte), com filmes "musicais" que projetariam a figura de Carmen Miranda.

A "vitória" dosamba sobre a modinha deve ser compreendida, em grande medida, como o sucesso de um gênero nascido já dentro dessas condições fundamentalmente urbanas e modernas sobre as formas musicais de extração mais tradicional. ${ }^{5}$ A velocidade com que o samba se consolida na posição de

4 É o caso de Ferdinand Denis, que em seu Resumo da história da literarura brasileira escreveu sobre "a propensão dos brasilciros para a música", acentuando referir-se aos "modestos artesãos [que] percorrem de noite as ruas, cantando as comoventes modinhas, que é impossivel a gente escutar sem se enternecer". Historiadores e críticos do Romantismo - l: a contribuição européia, crítica e história literária,p. 73-4. A propósito da história da modinha, ver ALVARENGA, Oneyda. Música popular brasileira, especialmente p. 227-35.

5 Comentando as origens do samba, José Ramos Tinhorão observa, em tom de lamento, que "contemporâneo do disco e do teatro de revista eminentemente musical, o samba nascia com o destino de passar às mãos dos compositores profissionais - que logo seriam Sinhô, Careca, Caninha, Donga, Pixinguinha, etc. -, e isso explica o seu estilo amaxixado dos primeiros tempos. Embora de origem popular, o samba começava logo corrompido pelo vício de execução dos integrantes de orquestras das gravadoras e do teatro musicado, àquela época impregnados do ritmo do maxixe, e começando a deixar-se influenciar pelos novos gêneros americanos do one-step, do ragtime, do black bottom, etc. [...] o samba ia acabar em pouco tempo não apenas com a polca e as chulas, mas com as toadas sertancjas... e a voga de motivos nordestinos". Em comentário sobre a marcha 
eixo da canção popular brasileira deve-se, entre outros fatores, à sua natureza eminentemente moderna. Nascido já como forma urbana "registrada e profissionalizada", através da gravação em disco e da reserva de direitos de autoria, o samba não hesitou, desde o primeiro momento, em adaptar-se às modas musicais do momento, inclusive estrangeiras, incorporando-as à sua base rítmica fundamental e dando-lhe o aspecto de gênero camaleônico (antropofágico?) tipicamente moderno.

A trajetória de Catulo da Paixão Cearense, artista nascido no Maranhão, mas ainda jovem emigrado para o Rio de Janeiro onde construiu toda sua carreira, é particularmente útil para entender as transformações pelas quais passou a cena musical carioca durante os anos críticos da ascensão do samba. Iniciando-se artisticamente ainda no século XIX como letrista e intérprete de modinhas, serestas e cantigas de sabor sertanejo, Catulo produziu material suficiente para onze volumes de coletâneas de suas letras e recitativos. Com o passar dos anos e o crescimento de sua popularidade, Catulo aproximou-se de certos nomes da intelectualidade (como Coelho Neto) e da política (como Rui Barbosa), vindo a se apresentar no auditório da Escola Nacional de Música, em 1908. Esse movimento de "ascensão" do artista popular, que se favorecia do interesse "populista" de nossas elites políticas e intelectuais é análogo ao que experimentaria o gênero do "samba-exaltação" ou do "samba-cidadão" nos anos 30 e $40{ }^{6}$ A diferença fundamental está no fato de Catulo ter permanecido "fiel" às forças que primeiro cooptaram sua produção artística, do mesmo modo que aferrou-se às formas básicas de seu projeto musical original, tornando-se incapaz de acompanhar as mudanças políticas e técnicas de sua época.

Traço expressivo das dificuldades de Catulo incorporar o moderno em sua prática artística pode ser visto, em um relato biográfico, contado em forma de crônica anedótica por Bastos Tigre. Funcionário que era do Ministério da Viação, Catulo fazia parte dos quadros do serviço público desempenhando a função de datilógrafo. De acordo com o cronista, Catulo, desde que fora nomeado, jamais comparecera à sua repartição, até porque não sabia datilografar. De fato, a nomeação tinha sido obtida através da simpatia de certo político

carnavalesca, forma irmã do samba, Tinhorão escreve que se trata de "criação típica de compositores da classe média da década de 20, ... [representando] mais o resultado do impacto de marchas portuguesas divulgadas no Brasil por companhias de teatro musicado nos primeiros anos do século, e depois pelo ritmo do ragtime americano". TINHORÃO, José Ramos. Pequena história da música popular: da modinha ao Tropicalismo, p. 124-126.

6 A propósito das relaçōes entre a canção popular e o Establishment político e cultural carioca nesse periodo ver o excelente ensaio de José Miguel Wisnik, "Getuilio da Paixão Cearense" (Villa-Lobos e o Estado Novo), In: O nacional e o popular na cultura brasileira: Música, p. 129-91. 
que estivera à frente do ministério como forma de assegurar ao artista a aposentadoria futura. No entanto, com o movimento de 1930 , todos os funcionários públicos foram convocados às suas repartiçōes de origem, com o que Catulo comparece pela primeira vez ao serviço. Depois de áspera discussāo com - porteiro do órgão, que não conhecia o "funcionário" ilustre, Catulo, já reconhecido como autor das velhas modinhas de sucesso, "reassume" suas funções. Nisso, o diretor da repartição, já informado de sua presença, apresentase ao compositor e, procurando ganhar-lhe a simpatia, pergunta ao poeta que tipo de máquina de escrever seria de sua predileção, ao que o artista teria respondido, após buscar na memória algum nome de máquina: "- Prefiro uma Singer". 7

A anedota contada por Bastos Tigre servia de contraponto humorístico ao tom grave do apelo que sua crônica endereçava às autoridades federais: aumentar a aposentadoria concedida ao artista com base nos poucos anos de serviço prestado como "datilógrafo" oficial, em vista de seus muitos anos "de trabalho de coração e cérebro pela nossa pátria", no que acabaria sendo atendido pelo então Presidente Getúlio Vargas.

Independentemente de veracidade estrita do diálogo entre Catulo e seu diretor, o texto de Bastos Tigre, ao enfatizar a falta de familiaridade do cancionista com o mundo das máquinas (nāo será irrelevante observar que o nome que lhe vem à cabeça, não apenas designa produto que não se encaixa no campo desejado, mas, sobretudo, corresponde à forma inglesa para "cantor"), aponta para o traço arcaizante e conservador do artista. Em outro trecho da mesma crônica, quando o artista tentava declinar da nomeação, alegando não saber escrever a máquina, ouviria de seu benfeitor o protesto: "- Então pensa que eu esperava que você fosse escrever versos a máquina?".

Essa vocação "caligrálica", artesanal, da produção de Catulo realizavase, do ponto de vista estético, através de um vocabulário arcaizante, preferência por temas rurais e investimento em formas musicais herdadas do século passado. Muito diferente da acuidade mercadológica de Sinhó, que já no final da década de 10, comparecia às festas da Penha acompanhado de grupo musical que exccutava maciçamente composiçōes de "sua autoria", numa estratćgia de

7 CEARENSE, Catullo da Paixāo. Op cit., p. 182-4.

8 Sobre o tema da máquina de escrever e do impacto de seu aparecimento na produção cultural brasileira do inicio do sóculo ver o capítulo "A mäo, a máquina", In: SOSSSEKIND, Flora. Cincmatógrafo de letras: literatura, técnica e modernizaçāo no Brasil, p.17-28. 
atuação sobre o gosto popular que prefigura a prática mais tarde executada em larga escala pelas gravadoras conhecida como "jabaculê"?

Contudo, essa inadequação de Catulo aos novos tempos da canção popular brasileira deveu-se menos a uma aversão intrinseca do artista aos modernos meios de produção e reprodução musical, e mais, à sua lentidão em buscar adaptar-se a eles. Com efeito, o livro que tem por introdução o depoimento amargo antes citado, constitui ele próprio uma tentativa tardia de adaptar sua obra a um formato que incorporasse em sua concepção as potencialidades dos novos mídia musicais. $O$ milagre de Sāo João é um poema dramático dividido em várias partes, resultante da expansão de um texto anterior do poeta, "Promessa", incluído originalmente na coletânea Meu sertão, de 1918. Procurando chamar a atenção do leitor para as virtudes de seu texto, o autor escreve:

Se é, na essência, a mesma coisa, no grande desenvolvimento que the dei, é outro poema. Tenho comigo todos os discos que o ilustram.

Por insinuações minhas, eles foram gravados há muitos anos $\mathrm{e}$ há muitos anos estão esgotados. Fosse eu um homem rico, mandaria gravá-los, de novo, para proveito dos leitores. Com eles, poderiam se convencer de que este "Milagre" é um verdadeiro milagre de poesia. É inútil dar o nome dos meus discos, porque é quase impossível serem hoje encontrados. ${ }^{10}$

Ao apresentar seu novo livro como a forma aprimorada de um antigo sucesso de sua autoria, Catulo utiliza-se com habilidade de uma estratégia de

9 Sobre essas estratégias de autopromoção de $\operatorname{Sinh} \delta$, que proclamou a si mesmo "Rei do samba", bem como as acusaçōes de plágio e roubo de canções tantas vezes levantadas contra 0 sambista ver ALENCAR, Edigar de. Nosso Sinhô do samba, em especial o capítulo IX, "Passarinhos pegados" (a Heitor dos Prazeres, de quem Sinh 6 confessadamente teria "expropriado" o samba de sucesso "Gosto que me enrosco", ele teria confidenciado que, de fato, em sua opiniảo, "samba era como passarinho, estava no ar, era do primeiro que pegasse", donde a ferina resposta musical do colega que perdera seu "canarinho" na composição "Rei dos meus sambas"). A questão da propriedade autoral nesse periodo é delicada. O próprio Catulo Cearense, elogiado por autores tão diferentes entre si quanto Lima Barreto e Coelho Neto por seus esforços dignificadores do violão e da modinha, esteve sob suspeição de plágio em nada menos do que o célebre "Luar do Sertão". Ary Vasconcelos informa que Almirante via esta composição, bem como "Cabóca de Caxangá", como temas folclóricos recolhidos originalmente por Joảo Pernambuco e espertamente recriados por Catulo Cearense. Panorama da mísica popular brasileira, v. I, p. 121.

10 CEARENSE, Catullo da Paixão. Op cit., p. 5-6. 
autopromoção, aproveitando para mencionar suas gravações musicais que funcionariam como útil complemento para o texto. Entretanto, ao lamentar a ausência de regravaçōes de seus discos, o artista evoca a figura de um "mecenas" que lhe garantisse, a fundo perdido, a reediçāo de sua produção fonogrática.

A seqüência de seu texto é, no entanto, ainda mais expressiva:

O leitor com seu gosto apurado e a sua inteligência, pode substitui-los [seus discos esgotados] por outros, antigos, ou mesmo modernos, desde que eles condigam com oassunto, a que se têm de adaptar. Sempre que funcionar o aparelho fonográfico, o leitor deve interromper a leitura, continuando-a depois de o disco terminado. Alguns discos poderão ser tocados na íntegra, outros em parte. “O Guarani”, por exemplo, será discado apenas nos primeiros compassos, salvo se o recitador resolver o contrário. Repito: recomendo todo o cuidado e inteligência na escolha desses discos. Se não forem bem escolhidos, en lugar de embelezarem, prejudicarão a beleza do poema. No fim de todo esse trabalho, ler-se-á una explicação mais desenvolvida sobre esse assunto."

Nesse momento o texto toma ares de "manual de instruçōes" para o leitor melhor usufruir de suas virtudes. O uso do ncologismo "discado" contrasta com a advertência quanto ao necessário escrutínio do leitor, que deve basear-se no "bom gosto e na inteligência" para sclecionar a trilla sonora que jamais irá sobrepor-se ao texto, servindo-lhe de moldura, espécie de vinheta sonora da leitura. As observaçōes ao final do livro às quais se refere o autor avançam no espirito de recomendação para manuseio do "produto" em questão.

A seguir, Catulo dá conta de sua concepção quanto à utilidade ou função dos mídia como relação ao seu trabalho:

Seria para mim uma fortuna, se aparecesse uma alma generosa que fizesse gravar este poema formidável, para que ele ficasse na Biblioteca Nacional ou no Insituto Histórico, afim (sic) de que, de aqui a 50,100, 200 ou 300 anos, quando ja tiverem desaparecido as festas das noites de S. João, e, até mesmo os sertões, os pósteros, com uma pequena máquina fonográfica, uns discos e umas tantas folhas de papel, pudessem reproduzir essas 
festas tradicionais, tudo o que se passa hoje nos sertões brasileiros, tudo que já vai morrendo e que morrerá com os progressos da civilização. ${ }^{12}$

A consciência do "progresso" faz com que o autor carregue seu trabalho de uma "pureza" documental, um valor etnográfico que o faria merecedor do patrocinio "generoso" de alguém que permitisse seu registro, não para fins comerciais, ou mesmo estéticos, mas com o propósito de servir de documento histórico-cultural. Sob esse aspecto, a aceitação da filtragem do trabalho artístico pclo fonógrafo não se dá com o fito comercial, mas fundamentalmente como forma de cristalizar sua condição arcaica e arcaizante.

Num misto de escandalosa imodéstia e patética amargura, Catulo admite a decadência de sua produção nos parágrafos linais do texto:

Já lá se foram os grandes sacerdotes da religião do culto das noites consteladas! Já ninguém mais canta meu divino repertório! Hoje os trovadores nem me conhecem! Olham para mim como um qualquer pobre diabo, um João ninguém! E esses pobres diabos tudo me devem! Se no meu tempo eles fossem vomitar as suas espurcícias nos salöes em que fui aclamado, seriam enxotados a vara de marmelo.

Passei da moda, é verdade! Mas a minha época foi gloriosa! Se a alma não fenece, como a matéria, eu hei de ver de aqui a séculos este Milagre de S. Jocio recitado, e irradiado ou cinematografado, pois para se ouvir e ver essa ópera verde, como a chamou Procópio, basta um simples aparelho fonográfico, uns discos e umas follhas de papel. ${ }^{13}$

Reconhecendo que o seu tempo já passara, Catulo explicita de una só vez a causa de sua decadencia artística e a inviabilidade de sua esperança de redenção póstuma através da máquina ('onógrafo ou cineınatógrafo): o contexto dos meios de comunicação de massa só reconliece os ritos do mercado. $O$ tom recitativo que marcou a produção madura de Catulo, em contraste com a dicção essencialmente cantada da juventude, revelam o esforço em deslocar-se de um registro essencialmente popular (as modinhas cantadas) para um tipo de produção que pudesse ganhar o favor das elites intelectuais de sua geração (a poesia

12 CEARENSE, Calulo da Paixāo. Op. cit. 6-7.

13 libid., p. 12. 
sertancja). Tal movimento é rigorosamente inverso ao realizado por Orestes Barbosa, que se iniciara como poeta simbolista epigonal, publicando dois volumes de poesias e chegando a candidatar-se à Academia Brasileira de Letras, na vaga aberta com a morte de João do Rio, e depois abandonaria a poesia "de livro" para mergulhar decididamente na canção popular, celebrizando-se como autor de inúmeras letras antológicas que vão da seresta exemplar (Chão de Estrelas, em parceria com Sílvio Caldas) ao samba clássico (Positivismo, que cle divide com Noel Rosa). ${ }^{14}$ Encarando o maquinário que fundamentava os mídia modernos como meros instrumentos de preservação e reprodução de uma forma cristalizada no passado, Catulo da Paixão Cearense deixava clara sua incomprecnsão com respeito à natureza "produtiva" dos meios técnicos de comunicação.

\section{***}

Em abril de 1995, foi lançado o primciro disco do conjunto carioca Familia Roitman. O grupo, surgido no linal da década passada, começou a atuar profissionalmente no meio publicitário e no circuito de bares com um repertório de Bossa Nova e Jovem Guarda. Com formação que inclui piano, violão, percussão e voz, o quarteto constituido de jovens rapazes brancos da classe média alta preferiu dedicar o seu trabalho de estréia ao eixo fundamental da MPB: o samba. ${ }^{15}$ Antes mesmo que se completasse o prazo minimo de meio século que Catulo da Paixão Cearense estabelecera para o desaparecimento das fontes folclóricas de sua obra, o que justificaria a preservação de seu trabalho como testcmunho de nosso passado cultural, un conjunto de rapazes do Rio de Janeiro, que toma por nome uma referência televisiva "clássica", a perversa vilã da novela de maior audiência da Rede Globo nas últimas duas décadas, escollıe homenagear, tirando do esquecimento, obras de Noel Rosa, Ismacl Silva, Wilson Morcira, Lamartine Babo, Assis Valente, Luis Reis e Haroldo Barbosa, todas da década de 30, ao lado de sambas de Cactano Veloso e Paulinho da Viola. A resenha jornalistica que anuncia o lançamento observa que "o jeito de cantar é antigo, impostado", embora elogic o resultado geral e seja entusiástica quanto à scleção do repertório. Conclui informando tratar-se de "produto para exportação", com lançamento previsto para breve na Europa, Japão e EUA.

14 Sobre o percurso biobibliografico de Orestes Barbosa, ver BARBOSA, Orestes. Chĩo de Estrelas. Pocsias escolhidas. Em especial o texto do oditor, J. Ozon, que abre a coletainea, nas p. 9-32.

15 RYFF, Luiz Antonio. "Jovens da Familia Roirman tocam pérolas da MPB em disco de estréia", Lr: Follha de S. Paulo, 17/04/95, p. 6-5. O disco mencionado foi lançado pelo selo Wamer e leva o titulo O samba nas regras da arte. 
"Se a alma não fenece", como sugeria Catulo, é de imaginar que ele tenha razões para supor, lá de onde esteja a nos acompanhar, ter sido vitima de uma derradeira vilania da terrível personagem de Vale tudo. ${ }^{16}$

\section{RESUMO}

Este artigo comenta aspectos da produção do poeta e letrista popular Catulo da Pai xão Cearense, estabelecendo um paralelo entre o percurso realizado por este artista $e$ a trajetória de alguns contemporâneos seus, como José Barbosa Silva, o Sinhô, e Orestes Barbosa, procurando estabelecer os modos de relação dos seus trabalhos com os modernos meios de produção/reprodução em massa. Para tanto, este artigo concentra-se no exame da significativa introdução de Catulo ao seu poema dramático $O$ milagre de São João.

Palavras-chave: música popular, modernização, meios de comunicação de massa

\section{ABSTRACT}

This article deals with aspects of Catulo da Paixão Cearense's work, a poet and lyricist. It tries to compare his work to the ones of others like José Barbosa Silva, whose nickname was Sinho, a popular samba composer, and Orestes Barbosa, who was a poet and lyricist as well. It attempts to understand the relationship between Cearense's work and the modem mass media, which were being consolidated in Brazil by his time. In order to do so, this article focuses on a preface written by Cearense himself, included in O milagre de Säo João, a book of his own.

16 Novela de Gilberto Braga, levada ao ar pela Rede Globo de Televisão em 1989, na qual a personagem Odete Roitman desempenhava a função de grande vilã. 


\section{REFERÊNCIAS BIBLIOGRÁFICAS}

ALENCAR, Edigar de. Nosso Sinhô do samba. Rio de Janeiro : Civilização Brasileira, (Retratos do Brasil, 67) 1968.

ALVARENGA, Oneyda. Música popular brasileira. 2.ed. São Paulo : Duas Cidades, (O baile das quatro artes) 1982.

BANDEIRA, Manuel. Crônica da Província do Brasil. Rio de Janeiro : Civilização Brasileira, 1937.

BARBOSA, Orestes. Chão de Estrelas. Poesias escolhidas. Rio de Janeiro, J. Ozon, 1965.

CEARENSE, Catulo da Paixão. O milagre de São Jocio. Rio de Janciro, : A Noite, [ s.d.]. HISTORIADORES e criticos do Romantismo - 1: a contribuiçăo europeia, crítica e história literária. Seleção e apresentaçāo [de] Guilhermino César. Rio de Janeiro : Livros Técnicos e Científicos; São Paulo, EDUSP, 1978.

RYFF, Luiz Antonio. "Jovens da Familia Roirman tocam pérolas da MPB em disco de estréia", In: Folha de S.Paulo, 17/04/95, p. 6-5.

SQUEFF, Enio; WISNIK, José Miguel. O nacional e o popular na cultura brasileira: Música. São Paulo : Brasiliense, 1982.

SUSSEKIND, Flora. Cinematógrafo de letras: literatura, técnica e modernização no Brasil. São Paulo : Cia. das Letras, 1987.

TINHORẢO, José Ramos. Pequena história da música popular: da modinha ao Tropicalismo. 5. ed., rev. e aum. São Paulo : Ant Editora, 1986.

VASCONCELOS, Ary. Panorama da música popular brasileira. São Paulo : Martins, 1964, 2 v.. 